\title{
Analisis Data Informasi untuk Perencanaan Sistem Informasi Politeknik Negeri Tanah Laut
}

\author{
Data Analysis Information for Information Systems Planning \\ Politeknik Negeri Tanah Laut
}

\author{
Eka Wahyu Sholeha*1, Bambang Soedijono WA ${ }^{2}$, Asro Nasiri ${ }^{3}$ \\ 1,2,3 Magister Teknik Informatika Universtias Amikom Yogyakarta \\ E-mail: *1eka.1005@students.amikom.ac.id, ${ }^{2}$ bambang.s@amikom.ac.id, \\ 3asro@amikom.ac.id
}

\begin{abstract}
Abstrak
Pengembangan sistem informasi yang tidak terencana secara sistematis akan mengakibatkan organisasi tidak memiliki skala prioritas proyek pengembangan SI/TI dan terkesan tambal sulam yang akan berdampak pada perununan produktivitas organisasi. Politeknik Negeri Tanah Laut (Politala) merupakan perguruan tinggi di Kabupaten Tanah Laut yang terletak di Kalimantan Selatan. Dengan perencanaan strategis sistem informasi pada Politala dapat mendukung rencana dan pengembangan bisnis ke depannya. Dalam upaya yang dilakukan untuk penerapan sistem informasi guna meningkatkan efisiensi kerja, keefektifan manajemen dan keunggulan kompetitif di suatu organisasi, maka dituntut untuk melakukan pemetaan informasi data sebagai acuan dalam menentukan pembuatan sistem informasi yang dibutuhkan agar sesuai dengan kebutuhan informasi yang ada. Dengan menggunakan metode Value Chain untuk menggambarkan aktivitas utama dan pendukung guna memetakan kebutuhan informasi data, dan menggunakan metode SWOT untuk menganalisis lingkungan sekitar Politala. Hasil dari penelitian ini adalah informasi data yang sesuai dengan aktifitas organisasi yang dapat menjadi acuan untuk perencanaan strategis sistem informasi lebih lanjut.
\end{abstract}

Kata Kunci - Perencanaan Strategis, Sistem Informasi, Informasi Data

\begin{abstract}
The systematic development of unplanned information systems will result in organizations not having the priority scale of IS / IT development projects and seemingly patchy that will have an impact on organizational productivity growth. Tanah Laut State Polytechnic (Politala) is a college in Tanah Laut Regency located in South Kalimantan. With strategic planning information systems at Politala can support plans and business development in the future. In an effort made to implement information systems to improve work efficiency, management effectiveness and competitive advantage in an organization, it is required to map data information as a reference in determining the information system needed to fit existing information needs. By using the Value Chain method to describe the main and supporting activities to map data information needs, and use the SWOT method to analyze the surrounding environment of Politala. The results of this study are data information that is in accordance with the activities of the organization which can be a reference for further strategic information system planning.
\end{abstract}

Keywords - Strategic Planning, Information Systems, Data Information 


\section{PENDAHULUAN}

Perkembangan Sistem Informasi dan Teknologi Informasi (SI/TI) yang sangat pesat saat ini, telah dianggap juga sebagai sumber daya yang sangat penting bagi organisasi (baik organisasi pemerintah maupun organisasi swasta) [1]. Tidak hanya berperan sebagai suatu dukungan semata, namun juga telah berperan sebagai key operational, high potential, peran strategis, dan dapat dimanfaatkan untuk mendukung efektivitas, efisiensi, dan produktivitas dalam organisasi [2].

Penerapan sistem informasi dalam sebuah organisasi memiliki tiga sasaran utama. Pertama, memperbaiki efisiensi kerja dengan melakukan otomasi berbagai proses mengelola informasi. Kedua, meningkatkan keefektifan manajemen dengan memuaskan kebutuhan informasi guna pengambilan keputusan. Ketiga, memperbaiki rasa pesaing atau meningkatkan keunggulan kompetitif organisasi dengan merubah gaya dan cara berbisnis [3].

Pengembangan sistem informasi yang tidak terencana secara sistematis akan mengakibatkan organisasi tidak memiliki skala prioritas proyek pengembangan SI/TI dan terkesan tambal sulam. Cara seperti ini akan berdampak pada perununan produktivitas organisasi [3]. Salah satu cara mengetahui manfaat penggunaan Teknologi Informasi adalah dengan cara mengkaji ulang bisnis melalui analisis masalah bisnis dan perubahan lingkungan serta mempertimbangkan SI/TI sebagai salah satu solusi [4].

Perencanaan strategis sistem informasi adalah pendekatan sistematis untuk menentukan mana yang paling efektif dan efisien berkaitan dengan kepuasan pemenuhan kebutuhan informasi [5]. Sistem informasi strategis digunakan sebagai penerapan strategi perusahaan yang terdiri atas sistem teknologi informasi di level manapun, yang tidak terbatas pada level strategis saja. Istilah strategis yang diartikan oleh manajer untuk mencapai tujuan perusahaan merupakan sebagai rencana skala besar yang berorientasi jangka panjang untuk berinteraksi dengan lingkungan yang kompetitif. Strategi merupakan sebuah rencana permainan yang dilakukan oleh perusahaan. Meskipun sebuah rencana tersebut tidak menjabarkan secara akurat dan terperinci tentang seluruh sumber daya yang digunakan pada masa mendatang (termasuk orang-orang, keuangan dan bahan baku), akan tetapi sebuah rencana dapat memberikan kerangka kerja bagi keputusan-keputusan manajerial. Suatu strategi mencerminkan kesadaran perusahaan tentang bagaimana, kapan, dan dimana perusahaan tersebut berkompetisi, akan melawan siapa dalam kompetisi tersbut dan untuk tujuan apa suatu perusahaan berkompetisi [6].

Dalam upaya yang dilakukan untuk penerapan sistem informasi untuk meningkatkan efisiensi kerja, meningkatkan keefektifan manajemen dan meningkatkan keunggulan kompetitif di suatu organisasi, maka dituntut untuk melakukan pemetaan informasi data sebagai acuan untuk menentukan pembuatan sistem informasi yang dibutuhkan sesuai dengan kebutuhan informasi yang disediakan.

Politeknik Tanah Laut (Politala) merupakan sebuah perguruan tinggi yang didirikan dan diselenggarakan oleh Yayasan Pendidikan Tuntung Pandang Berseri Pelaihari bekerja sama dengan Pemerintah Kabupaten Tanah Laut yang terletak di Kalimantan Selatan. Pendirian Politala merupakan wujud keinginan dan kesepahaman bersama antara Pemerintah Daerah dan masyarakat Kabupaten Tanah Laut yang melihat kenyataan bahwa di daerah ini sangat membutuhkan sebuah perguruan tinggi dengan mempertimbangkan berbagai aspek, antara lain: jumlah lulusan SLTA yang setiap tahunnya berkisar antara 1.800-2.000 orang siswa, semakin kritisnya kondisi alam akibat industri tambang, dan semakin banyaknya berdiri perusahaan yang bergerak di bidang industri. Politala mempunyai visi "Terdepan dalam pengembangan ilmu, teknologi dan industri” dan beberapa misi diantaranya "Menyelenggarakan kegiatan penelitian yang berkualitas dengan orientasi pemanfaatan ilmu terapan dan teknologi”.

Perencanaan strategis sistem informasi pada Politala akan dapat mendukung rencana dan pengembangan bisnis kedepannya. Penerapan sistem informasi akan dirasa bermanfaat dan memberikan nilai apabila sesuai dengan visi, misi dan tujuan organisasi. Perencanaan strategis sistem informasi pun juga harus selaras dengan strategi bisnis. Dalam perencanaan strategis sistem informasi juga perlu disesuaikan dengan kondisi organisasi baik internal maupun eksternal. 
Untuk mengetahui sistem informasi yang akan diterapkan, maka perlu dilakukan analisa terlebih dahulu terhadap informasi data yang dibutuhkan di aktivitas tersebut. Karena sebuah sistem informasi memerlukan data informasi agar menjadi sistem yang sesuai dengan kebutuhan.

Berdasarkan latar belakang tersebut maka diperoleh rumusan masalah yaitu informasi apa yang dibutuhkan untuk kebutuhan perencanaan sistem informasi kedepannya. Adapun tujuan dari penelitian ini yaitu membuat data informasi untuk kebutuhan perencanaan sistem informasi kedepannya.

Beberapa penelitian yang telah dilakukan sebelumnya yang akan menjadi referensi dalam penelitian ini, yaitu penelitian yang diteliti oleh Ina Sholihah Widiati dkk, membahas tentang perencanaan strategis dan pemodelan arsitektur teknologi pada Sekolah Islam Terpadu Salman Al Farisi Yogyakarta. Penelitian tersebut menggunakan framework Ward and Peppard dengan permasalahan bagaimana membuat perencanaan strategis sistem informasi dan portofolio rekomendasi beserta roadmap sistem informasi mendatang untuk meningkatkan keunggulan kompetitif dengan menyelaraskan strategi bisnis organisasinya. Dimana hasil akhir dari penelitian ini diperoleh 15 usulan sistem informasi mendatang yang telah dipetakan dalam rencana pembangunan dalam jangka waktu 5 tahun mendatang [7].

Penelitian selanjutnya yang dilakukan oleh Julianto dkk, yang bertujuan untuk menganalisa area bisnis perusahaan, untuk membuat informasi yang bersifat strategis menjadikan sistem informasi perusahaan lebih efektif dan efisien dalam bersaing. Hasil dari penelitian ini merupakan blueprint teknologi sistem informasi yang menyarankan penambahan aplikasi seperti E-Supply Chain Management, E-Customer Relationship Management, Sistem Informasi Akuntansi, Aplikasi Penjualan Berbasis Mobile, yang bisa membantu perusahaan dalam memberikan pelayanan yang terbaik kepada pelanggan dan dapat memasarkan produk ke pangsa pasar yang lebih luas [8].

Penelitian selanjutnya yang berkaitan dengan perencanaan sistem informasi yang dilakukan oleh Gusti Syarifudin yang memiliki tujuan untuk meningkatkan daya saing STMIK Pontianak dengan perencanaan sistem informasi pengukuran kinerja dosen menggunakan pendekatan IT Balanced Scorecard. Hasil dari penelitian ini peneliti mengatakan bahwa pengukuran kinerja dosen yang sudah diterapkan menghasilkan informasi yang kurang valid dan control yang dilakukan kurang efektif [9].

Dari beberapa referensi diatas, penelitian ini lebih membahas tentang langkah awal sebelum melakukan perencanaan strategi lebih lanjut, yaitu dengan menganalisis value chain yang ada pada Politala dan mengetahui kekuatan, kelemahan, peluang serta sebuah ancaman yang ada pada Politala. Dengan adanya analisis tentang informasi yang diberikan dari setiap aktivitas pada value chain maka bisa didapatkan kesimpulan sistem informasi yang dibutuhkan sesuai kebutuhan informasi yang disediakan.

\section{METODE PENELITIAN}

\subsection{Value Chain}

Analisis value chain merupakan alat analisis yang berguna untuk memahami aktivitasaktivitas yang membentuk nilai suatu produk atau jasa dan digunakan untuk menciptakan nilai bagi pelanggannya dalam mencapai suatu keunggulan yang kompetitif. Tujuan analisis value chain adalah untuk mengidentifikasi tahap-tahap value chain dimana perusahaan dapat meningkatkan value untuk pelanggan atau untuk menurunkan biaya. Penurunan biaya atau peningkatan nilai tambah dapat membuat perusahaan lebih kompetitif [10]. Dalam rantai nilai yang umum, aktivitas pendukung terdiri dari infrastruktur perusahaan, pengelolaan sumber daya manusia, pengembangan teknologi dan usaha memperolehnya. Sedangkan dalam aktivitas utama terdiri dari logistik masuk, operasi, logistik keluar, pemasaran dan penjualan serta pelayanan, seperti tertera pada Gambar 1. 


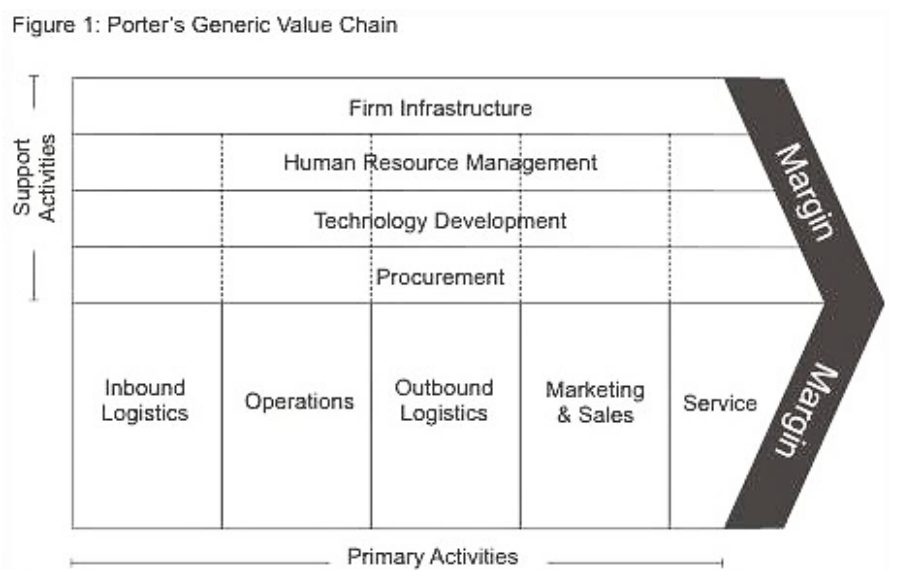

Gambar 1. Value Chain

\section{Aktivitas Utama (Primary Activities)}

Aktivitas-aktivitas utama pada perusahaan yang pada akhirnya memberikan kepuasan pada pelanggan. Aktivitas-aktivitas tersebut tidak hanya dilakukan dengan baik, tapi juga harus saling berhubungan dengan efektif jika keseluruhan performa bisnis hendak dioptimalkan. Aktivitas utama terdiri dari inbound logistic, outbound logistics, sales \& marketing dan services.

a. Inbound Logistics

Mendapatkan, menerima, menyimpan, dan pengadaan input kunci dan sumber daya dalam kualitas dan kuantitas yang tepat bagi bisnis.

b. Operations

Mengubah input menjadi produk atau layanan yang diperlukan oleh para pelanggan.

c. Outbound Logistics

Mendistribusikan produk ke pelanggan baik secara langsung kepada pelanggan atau ke agen yang sesuai untuk didistribusi, sehingga pelanggan dapat memperoleh produk atau jasa dan membayarnya dengan tepat.

d. Marketing \& Sales

Menyediakan cara-cara di mana pelanggan dan konsumen sadar akan produk atau jasa dan bagaimana mereka dapat memperoleh itu, termasuk cara untuk membujuk mereka untuk membeli atau menggunakan produk atau jasa.

e. Service

Memberikan nilai tambah lebih jauh kepada pelanggan dengan memastikan pelanggan mendapatkan keuntungan penuh atau nilai dari produk yang dibeli.

\section{Aktivitas Pendukung (Support Activities)}

Merupakan aktivitas yang dibutuhkan untuk mengontrol dan mengembangkan bisnis dari waktu ke waktu dengan cara menambahkan nilai secara tidak langsung, nilainya akan diketahui melalui kesuksesan dari aktivitas utama.

a. Firm Infrastructure

Infrastruktur merupakan sarana dan prasarana yang diperlukan oleh perusahaan.

b. Human Resource Management

Merupakan cara dari perusahaan dalam mengatur SDMnya, misalnya dengan memberikan pelatihan atau pembekalan skill dan ilmu.

c. Technology Development

Menjelaskan teknologi apa saja yang digunakan dalam perusahaan tersebut.

d. Producement

Suatu proses lengkap untuk mendapatkan barang dan jasa dari persiapan mulai dari persiapan dan pengolahan dari sebuah daftar permintaan atas invoice untuk pembayaran. 


\subsection{SWOT}

Analisis SWOT adalah identifikasi berbagai faktor secara sistematis untuk merumuskan strategi organisasi. Analisis ini didasarkan pada logika yang dapat memaksimalkan kekuatan (Strenght), dan peluang (Oppurtunities), namun secara bersamaan dapat memaksimalkan kelemahan (Weakness) dan ancaman (Threat) [11]. Adapun diagram analisis SWOT yang dijadikan acuan untuk indentifikasi berbagai faktor kekuatan, peluang, kelemahan serta ancaman dapat dilihat pada Gambar 2.

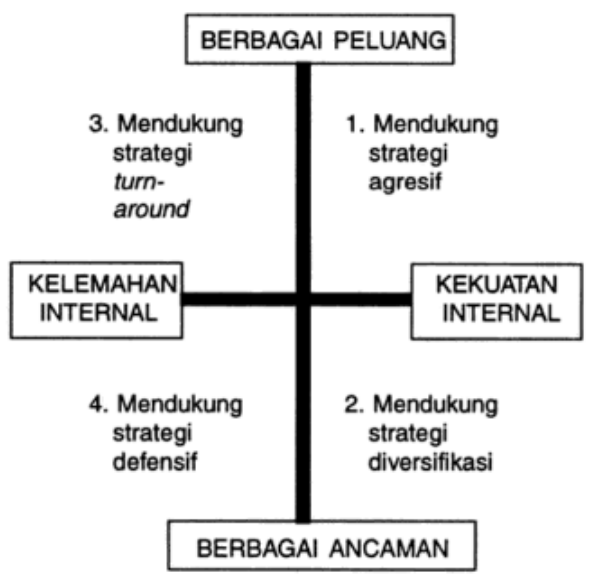

Gambar 2. Diagram Analisis SWOT

\section{HASIL DAN PEMBAHASAN}

\subsubsection{Analisis Proses Kegiatan Akademik Menggunakan Value Chain}

Analisis Value Chain merupakan metode untuk merinci suatu rangkaian dari bahan baku hingga produksi akhir, yang dibagi menjadi 2 aktivitas yaitu aktivitas utama dan aktivitas pendukung. Adapun hasil analisis Value Chain pada Politeknik Negeri Tanah Laut yang sudah digambarkan dalam kerangka value chain dapat dilihat pada Gambar 3 di bawah ini.

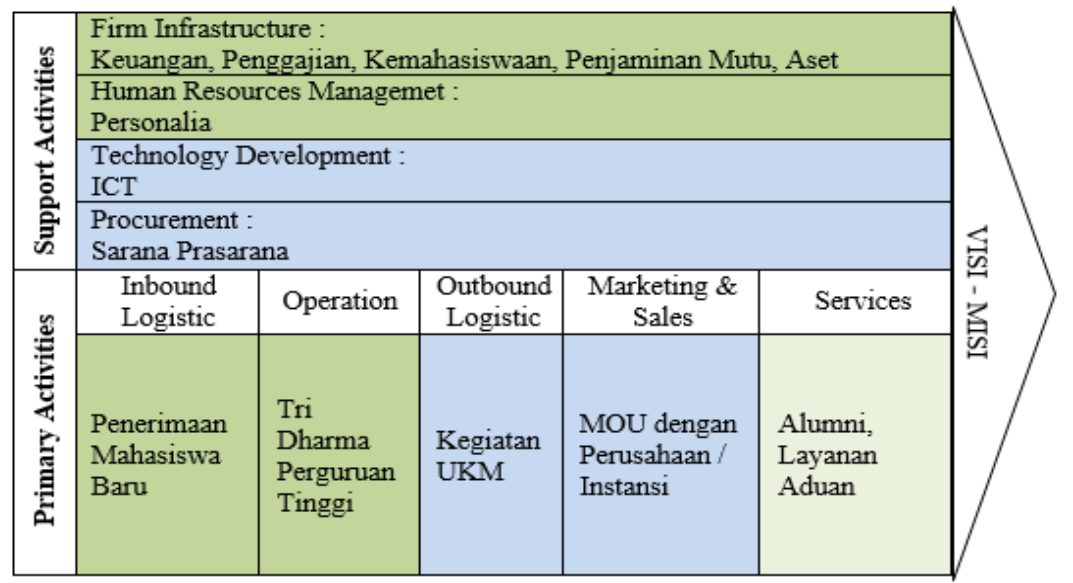

Gambar 3. Value Chain Politeknik Negeri Tanah Laut

Note :

Tersedia

Tersedia tapi belum berfungsi seutuhnya

Belum Tersedia 
Dari value chain di atas kemudian diuraikan proses kegiatan menjadi 2, yaitu aktivitas utama dan aktivitas pendukung, yaitu:

1. Aktivitas Utama (Primary Activities)

a. Penerimaan Mahasiswa Baru

Aktivitas ini merupakan kegiatan rutin tahunan Politeknik Negeri Tanah Laut pada setiap awal tahun ajaran baru. Data informasi yang dibutuhkan pada aktivitas ini adalah data calon mahasiswa untuk mengetahui biodata dan asal sekolah.

b. Tri Dharma Perguruan Tinggi

Pada aktivitas ini adalah kegiatan inti dalam sebuah perguruan tinggi yang dilakukan untuk memastikan bahwa kegiatan belajar mengajar berjalan dengan baik, yang meliputi penyusunan jadwal perkuliahan, penyusunan kurikulum, ujian praktek, ujian semester, penelitian yang dilakukan dosen maupun mahasiswa dan penghitungan nilai perkuliahan.

c. Kegiatan UKM

Aktivitas ini adalah untuk pengembangan diri mahasiswa diluar kelas.

d. MOU dengan Perusahaan / Instansi

Aktivitas ini untuk menjalin kerjasama dengan dunia usaha atau dunia industri guna kerjasama untuk kerja praktek dan bursa kerja.

e. Alumni dan Layanan Aduan

Kegiatan ini merupakan service yang dilakukan oleh alumni Politala yang bertujuan mengimplementasikan pelajaran yang sudah di dapat untuk menyelesaikan permasalahan yang ada pada masyarakat sekitar.

2. Aktivitas Pendukung (Support Activities)

a. Keuangan, Penggajian, Kemahasiswaan, Penjaminan Mutu

Merupakan bagian untuk pengelolaan keuangan, penggajian, kemahasiswaan serta penjaminan mutu yang ada pada Politala.

b. Personalia

Aktivitas ini untuk mendukung pengelolaan sumber daya manusia yang ada pada Politala, seperti pengelolaan data karyawan dan dosen beserta pengawasan kinerja dosen dan karyawan.

c. ICT

Aktivitas ini berguna untuk memanajemen IT serta pelaporan kondisi IT yang ada di Politala.

d. Sarana dan Prasarana

Digunakan untuk mengelola aset sarana prasarana Politala.

Tabel 1 berikut merupakan tabel dari aktivitas bisnis di bagian aktivitas utama pada Politeknik Negeri Tanah Laut yang menjabarkan mengenai informasi yang dibutuhkan beserta status Sistem Informasi nya.

Tabel 1. Aktivitas Bisnis pada Aktivitas Utama

\begin{tabular}{|c|c|c|c|}
\hline No & Aktivitas Bisnis & Informasi yang dibutuhkan & Status SI \\
\hline 1 & $\begin{array}{l}\text { Penerimaan } \\
\text { Mahasiswa Baru }\end{array}$ & - Informasi data calon mahasiswa & - Tersedia \\
\hline 2 & $\begin{array}{l}\text { Tri Dharma } \\
\text { Perguruan Tinggi }\end{array}$ & $\begin{array}{l}\text { - Informasi jadwal perkuliahan } \\
\text { - Informasi materi perkuliahan } \\
\text { - Informasi akademik } \\
\text { - Informasi perpustakaan } \\
\text { - Informasi mengenai PKL } \\
\text { (Praktek Kerja Lapangan) } \\
\text { - Informasi mengenai tugas akhir }\end{array}$ & $\begin{array}{l}\text { - Belum Tersedia } \\
\text { - Tersedia } \\
\text { - Tersedia } \\
\text { - Tersedia } \\
\text { - Tersedia } \\
\text { - Tersedia }\end{array}$ \\
\hline 3 & Kegiatan UKM & - Informasi UKM yang ada & - Belum Tersedia \\
\hline
\end{tabular}


Citec Journal, Vol. 5, No. 2, Februari 2018 - April 2018

ISSN: 2460-4259

\begin{tabular}{|l|l|l|l|}
\hline No & Aktivitas Bisnis & \multicolumn{1}{|c|}{ Informasi yang dibutuhkan } & \multicolumn{1}{c|}{ Status SI } \\
\hline 4 & $\begin{array}{l}\text { MOU dengan } \\
\text { perusahaan atau } \\
\text { instansi }\end{array}$ & $\begin{array}{l}\text { ・ Informasi instansi atau } \\
\text { perusahaan yang sudah atau } \\
\text { belum melakukan MOU }\end{array}$ & $\bullet$ Belum Tersedia \\
\hline 5 & $\begin{array}{l}\text { Alumni dan } \\
\text { Layanan Aduan }\end{array}$ & $\begin{array}{l}\bullet \text { Informasi mengenai data alumni } \\
\bullet \text { Layanan aduan dan aspirasi }\end{array}$ & $\begin{array}{l}\bullet \text { Tersedia } \\
\bullet \text { Tersedia }\end{array}$ \\
\hline
\end{tabular}

Tabel 2 di bawah ini merupakan tabel dari aktivitas bisnis di bagian aktivitas pendukung pada Politeknik Negeri Tanah Laut yang menjabarkan mengenai informasi yang dibutuhkan beserta status Sistem Informasinya.

Tabel 2. Aktivitas Bisnis pada Aktivitas Pendukung

\begin{tabular}{|c|c|c|c|}
\hline $\mathrm{No}$ & Aktivitas Bisnis & Informasi yang dibutuhkan & Status SI \\
\hline 1 & $\begin{array}{l}\text { Keuangan, } \\
\text { Penggajian, } \\
\text { Kemahasiswaan, } \\
\text { Penjaminan Mutu }\end{array}$ & $\begin{array}{l}\text { - Informasi keuangan } \\
\text { - Informasi Penggajian } \\
\text { - Informasi Kemahasiswaan } \\
\text { - Informasi Penjaminan Mutu }\end{array}$ & $\begin{array}{l}\text { - Belum Tersedia } \\
\text { - Belum Tersedia } \\
\text { - Belum Tersedia } \\
\text { - Belum Tersedia }\end{array}$ \\
\hline 2 & Personalia & - Informasi kepegawaian & - Tersedia \\
\hline 3 & ICT & - Informasi daftar IT & - Belum Tersedia \\
\hline 4 & $\begin{array}{l}\text { Sarana dan } \\
\text { Prasarana }\end{array}$ & $\begin{array}{l}\text { - Informasi daftar sarana dan } \\
\text { prasarana }\end{array}$ & - Belum Tersedia \\
\hline
\end{tabular}

Setelah melakukan analisis aktivitas bisnis menggunakan value chain, maka didapat kebutuhhan sistem informasi seperti pada Tabel 3 yang disesuaikan dengan aktivitas bisnis dan kebutuhan informasi yang digunakan.

Tabel 3. Kebutuhan sistem informasi

\begin{tabular}{|c|c|c|c|}
\hline No & Aktivitas Bisnis & Informasi yang dibutuhkan & $\begin{array}{l}\text { Kebutuhan Sistem } \\
\text { Informasi }\end{array}$ \\
\hline 1 & $\begin{array}{l}\text { Tri Dharma } \\
\text { Perguruan Tinggi }\end{array}$ & - Informasi jadwal perkuliahan & $\begin{array}{l}\text { - Sistem Informasi Jadwal } \\
\text { Perkuliahan }\end{array}$ \\
\hline 2 & Kegiatan UKM & - Informasi UKM yang ada & - Sistem Informasi UKM \\
\hline 3 & $\begin{array}{l}\text { MOU dengan } \\
\text { perusahaan atau } \\
\text { instansi }\end{array}$ & $\begin{array}{l}\text { - Informasi instansi atau } \\
\text { perusahaan yang sudah atau } \\
\text { belum melakukan MOU }\end{array}$ & - Sistem Informasi Humas \\
\hline 4 & $\begin{array}{l}\text { Keuangan, } \\
\text { Penggajian, } \\
\text { Kemahasiswaan, } \\
\text { Penjaminan Mutu }\end{array}$ & $\begin{array}{l}\text { - Informasi keuangan } \\
\text { - Informasi Penggajian } \\
\text { - Informasi Kemahasiswaan } \\
\text { - Informasi Penjaminan Mutu }\end{array}$ & $\begin{array}{l}\text { - Sistem Informasi } \\
\text { Keuangan } \\
\text { - Sistem Informasi } \\
\text { Penggajian } \\
\text { - Sistem Informasi } \\
\text { Kemahasiswaan } \\
\text { - Sistem Informasi } \\
\text { Penjaminan Mutu }\end{array}$ \\
\hline 5 & ICT & - Informasi daftar IT & - Sistem Informasi Aset IT \\
\hline 6 & $\begin{array}{l}\text { Sarana dan } \\
\text { Prasarana }\end{array}$ & $\begin{array}{l}\text { - Informasi daftar sarana dan } \\
\text { prasarana }\end{array}$ & $\begin{array}{l}\text { - Sistem Informasi Aset } \\
\text { Sarana dan Prasarana }\end{array}$ \\
\hline
\end{tabular}




\subsubsection{Analisis Faktor Internal dan Eksternal menggunakan SWOT}

Analisis SWOT yang dilakukan untuk mengetahui faktor-faktor yang menjadi kekuatan, kelemahan, kesempatan dan ancaman yang ada di Politeknik Negeri Tanah Laut tersebut dijelaskan pada Tabel 4.

Tabel 4. Analisis SWOT Politeknik Negeri Tanah Laut

\begin{tabular}{|c|c|}
\hline Strengths (S) & Weakness (W) \\
\hline $\begin{array}{l}\text { - Adanya UKM untuk mendukung } \\
\text { mengembangkan akademik mahasiswa } \\
\text { - Sarana dan prasarana merupakan milik } \\
\text { sendiri } \\
\text { - Memiliki fasilitas yang lengkap, seperti } 6 \\
\text { lab, } 1 \text { bengkel mesin otomotif, wifi, } \\
\text { perpustakaan, musholla dan koperasi. } \\
\text { - Adanya ICT sebagai pengendali dan } \\
\text { pengembang SI/TI } \\
\text { - Dukungan dari yayasan untuk peningkatan } \\
\text { kualitas dosen untuk melanjutkan S2/S3, } \\
\text { serta mendorong dan menyertakan dosen } \\
\text { untuk mengikuti kegiatan ilmiah, seperti } \\
\text { pelatihan, seminar, dll. } \\
\text { - Stakeholder sebagaian besar sudah mampu } \\
\text { mengoperasikan TI/SI }\end{array}$ & $\begin{array}{l}\text { - Terbatasnya jumlah bandwith internet } \\
\text { - Kurangnya dosen berkualifikasi magister } \\
\text { dan doktor di bidangnya } \\
\text { - Kurangnya minat dosen dalam melakukan } \\
\text { penelitian-penelitian baru } \\
\text { - Banyak sistem informasi yang belum } \\
\text { berfungsi dengan baik }\end{array}$ \\
\hline Opportunities (O) & Threats (T) \\
\hline $\begin{array}{l}\text { - Menjalin kerjasama dengan berbagai } \\
\text { instansi/dinas pemerintah atau swasta } \\
\text { - Fasilitas internet sudah menjangkau seluruh } \\
\text { kawasan kampus } \\
\text { - Memiliki banyak sistem informasi } \\
\text { membuka kesempatan untuk memperoleh } \\
\text { berbagai informasi untuk memberikan } \\
\text { konstribusi peninkatan kualiatas Politeknik }\end{array}$ & $\begin{array}{l}\text { - Pertumbuhan dan perkembangan IPTEK } \\
\text { yang signifikan, mengharuskan } \\
\text { penyesuaian kurikulum terhadap kebutuhan } \\
\text { pasar } \\
\text { - Persaingan antar perguruan tinggi yang } \\
\text { semakin ketat sehingga Politehnik } \\
\text { mengharuskan menjaga kualitas dalam hal } \\
\text { pendidikan }\end{array}$ \\
\hline
\end{tabular}

Setelah melakukan analisis SWOT maka fakta-fakta yang didapat diolah kembali untuk menjadi sebuah strategi dari SWOT yang dijelaskan pada tabel 5.

Tabel 5. Matriks SWOT

\begin{tabular}{|l|l|}
\hline \multicolumn{1}{|c|}{ Strategi - SO } & \multicolumn{1}{c|}{ Strategi - WO } \\
\hline - Kerjasama dengan instansi dan dinas & - Meningkatkan Bandwith \\
- Memanfaatkan SI untuk membuat & - Membuka lowongan dosen lebih banyak \\
Politeknik Negeri Tanah Laut lebih unggul & yang berpendidikan tinggi \\
& - Sistem Informasi lebih dimaksimalkan dan \\
& di update secara berkala \\
\hline \multicolumn{1}{|c|}{ Strategi - ST } & \multicolumn{1}{c|}{ Strategi - WT } \\
\hline - Perlu memotivasi para dosen agar selalu & - Meningkatkan kualitas pendidikan dosen \\
melakukan penelitian secara berkala & agar dapat bersaing dengan perguruan \\
mengikuti perkembangan IPTEK & tinggi lainnya \\
- Memanfaatkan SI untuk persaingan antar & \\
perguruan tinggi & \\
\hline
\end{tabular}


Citec Journal, Vol. 5, No. 2, Februari 2018 - April 2018

\subsubsection{Roadmap Portofolio Sistem Informasi}

Adapun roadmap portofolio untuk rencana pembangunan dan pengembangan sistem informasi yang ditemukan dan dibuat dalam jangka wajtu tiga tahun (3) kedepan pada Politeknik Negeri Tanah Laut, masing-masing sistem informasi yang akan dibangun seperti pada tabel 6 .

Tabel 6. Roadmap Portofolio sistem informasi Politala

\begin{tabular}{|c|l|c|c|c|}
\hline \multirow{2}{*}{ No } & \multicolumn{1}{|c|}{ Sistem Informasi } & \multicolumn{3}{|c|}{ Tahun } \\
\cline { 3 - 5 } & & 2019 & 2020 & 2021 \\
\hline 1 & Sistem Informasi keuangan & & & \\
\hline 2 & Sistem Informasi Penggajian & & & \\
\hline 3 & Sistem Informasi Jadwal Perkuliahan & & & \\
\hline 4 & Sistem Informasi Humas & & & \\
\hline 5 & Sistem Informasi Kemahasiswaan & & & \\
\hline 6 & Sistem Informasi Penjaminan Mutu & & & \\
\hline 7 & Sistem Informasi Aset IT & & & \\
\hline 8 & Sistem Informasi Sarana dan Prasarana & & & \\
\hline 9 & Sistem Informasi UKM & & & \\
\hline
\end{tabular}

\section{KESIMPULAN}

Berdasarkan hasil penelitian dan pembahasan, maka dapat ditarik kesimpulan, yaitu:

1. Masih ada beberapa aktivitas yang belum menggunakan sistem informasi.

2. Diperoleh 9 sistem informasi yang sudah berjalan dan 9 sistem informasi yang belum tersedia.

3. Berdasarkan roadmap portofolio sistem informasi yang diperlukan sebanyak 9 sistem informasi yaitu, Sistem informasi keuangan, Sistem informasi penggajian, Sistem informasi jadwal perkuliahan, Sistem informasi humas, Sistem informasi kemahasiswaan, Sistem informasi penjaminan mutu, Sistem informasi aset IT, Sistem informasi sarana dan prasarana, Sistem informasi UKM. Berdasarkan waktu rencana implementasi setidaknya diperlukan waktu 3 tahun agar perencanaan strategis sistem informasi dapat diimplementasikan maksimal.

\section{SARAN}

Saran yang diberikan untuk pengembangan lebih lanjut dari penelitain ini adalah perlu dilakukannya perencanaan sistem informasi apa yang dibutuhkan sesuai kebutuhan informasi yang sudah dipetakan untuk menunjang aktivitas yang sudah berjalan, tetapi harus dilakukan analisis internal dan eksternal lingkungan Politeknik Negeri Tanah Laut terlebih dahulu, agar gambaran sekitar Politeknik Negeri Tanah Laut lebih jelas.

\section{DAFTAR PUSTAKA}

[1] Hammer, M., Champy, J., 1993, Reengineering The Corporation. Nicholas Brealey Publishing Ltd, London.

[2] Wheelan, T. L., Hunger, J. D., 2004, Strategic Management and Business Policy, Prentice Hall, New Jersey.

[3] Ward, J., \& Peppard, J., 2002, Strategic Planning for Information System (2nd ed), John Wiley \& Sons, New York. 
[4] Earl, M. 1996. Manajemen Strategies for Information Technology, Prentice Hall, United States.

[5] Ward, J., and Griffiths, P., 1996, Strategic Planning for Information Systems, John Wiley \& Sons, New York.

[6] Pearce II, John A., dan Robinson, Richard B. 2011. Strategic Management : Formulation, Implementation and Control, McGraw-Hill Education, Pennsylvania Plaza.

[7] Widiati, I.S., Utami, E., Henderi. 2015. Perencanaan Strategis Sistem Informasi Untuk Meningkatkan Keunggulan Kompetitif Sekolah Islam Terpadu. Citec Journal, Vol. 2, No. 4, Hal 329 - 340.

[8] Julianto., Minarto, G.B., Ridwan, E., 2018. Perencanaan Strategis Sistem Informasi Pada PD Solaris Inti Persada Pontianak. Seminar Nasional Sistem Informasi dan Teknologi Informasi (SENSITEK). Pontianak, 12 Juli.

[9] Syarifudin, G., 2013. Perencanaan Strategis Sistem Informasi Pengukuran Kinerja Dosen dengan Menggunakan IT-Balance Scorecard. Jurnal Ilmiah SISFONTETIKA. Vol. 3, No. 1, Hal 61 - 70.

[10] Wisdaningrum, O., 2013. Analisis Rantai Nilai (Value Chain) Dalam Lingkungan Perusahaan. Jurnal ANALISA. Vol. 1, No. 1. Hal 40 - 48.

[11] Rangkuti. F., 2006. Teknik Mengukur dan Strategi Meningkatkan Kepuasan Pelanggan, Gramedia Pustaka Utama, Jakarta 